\title{
Neurocutaneous melanocytosis
}

INSERM

\section{Source}

INSERM. (1999). Orphanet: an online rare disease and orphan drug data base.

Neurocutaneous melanocytosis. ORPHA:2481

Neurocutaneous melanocytosis (NCM) is a rare congenital neurological disorder characterized by abnormal aggregations of nevomelanocytes within the central nervous system (leptomening eal melanocytosis) associated with large or giant congenital melanocytic nevi (CMN; see this term). NCM can be asymptomatic or present as variably severe and progressive neurological impairment, sometimes resulting in death. 